\title{
Impaired function of endothelial progenitor cells in children with primary systemic vasculitis
}

\author{
Ying Hong ${ }^{*}$, Despina Eleftheriou, Nigel J. Klein and Paul A. Brogan
}

\begin{abstract}
Introduction: Previously, we demonstrated that children with active systemic vasculitis (SV) have higher circulating CD34 + CD133 + KDR+ endothelial progenitor cells (EPC); the function of these EPCs, and their relationship with disease activity in vasculitis remains largely unexplored. We hypothesized that although EPC numbers are higher, EPC function is impaired in active SV of the young. The aims of this study were therefore to: 1. investigate the relationship between disease activity and EPC function in children with SV; and 2. study the influence of systemic inflammation on EPC function by investigating the effects of hyperthermia and TNF-a on EPC function.

Methods: We performed a cross-sectional study of unselected children with SV with different levels of disease activity attending a single center (Great Ormond Street Hospital, London) between October 2008 and December 2014. EPCs were isolated from peripheral blood of children with SV, and healthy child controls. EPC function was assessed by their potential to form colonies (EPC-CFU), and ability to form clusters and incorporate into human umbilical vein endothelial cell (HUVEC) vascular structures in matrigel. The effects of hyperthermia and TNF-a on EPC function were also studied.

Results: Twenty children, median age 12-years (5-16.5; nine males) were studied. EPC-CFU and the number of EPC clusters formed on matrigel were significantly reduced in children with active vasculitis compared with healthy controls ( $p=0.02$ for EPC-CFU; $p=0.01$ for EPC cluster formation). Those with active vasculitis had lower EPC-CFU and EPC cluster formation than those with inactive disease, although non-significantly so. In addition, EPC incorporation into matrigel HUVEC networks was lower in children with SV compared with healthy children, irrespective of disease activity. Ex-vivo pre-treatment of EPC with hyperthermia impaired EPC function; TNF-a down-regulated EPC expression of CD18/CD11b and resulted in decreased incorporation into HUVEC networks.
\end{abstract}

Conclusions: Whilst our previous work showed that circulating CD34 + EPC numbers are well preserved, this study revealed that EPC function is significantly impaired in children with vasculitis. It is possible that the chronic inflammatory milieu associated with vasculitis may impair EPC function, and thus contribute to an unfavourable balance between endothelial injury and repair. The mechanism of this remains to be established, however.

Keywords: Endothelial progenitor cells, Vasculogenesis, Matrigel, Inflammation, Vasculitis

\section{Introduction}

Systemic vasculitis (SV) of the young is characterised by systemic inflammation, endothelial activation, and (in some cases) necrosis of blood vessel walls leading to multi-organ injury $[1,2]$. Endothelial activation and injury are central to the pathogenesis of SV with increased endothelial cell adhesion molecule expression, and a switch to a prothrombotic endothelial phenotype, both of which contribute to the

\footnotetext{
* Correspondence: y.hong@ucl.ac.uk

Infection, Immunity, Immunology and Physiological Medicine, Institute of Child Health, University College London, 30 Guilford Street, London WC1N $1 \mathrm{EH}, \mathrm{UK}$
}

vascular pathology of SV [3, 4]. In addition to this severe endothelial injury, it has been suggested that endothelial repair processes may also be impaired $[5,6]$, and thus SV could be particularly damaging to the cardiovascular system due to an unfavourable imbalance between endothelial injury and repair, as is the case in other diseases targeting the endothelium $[7,8]$.

It is now known that recruitment of bone marrowderived endothelial progenitor cells (EPC) represents an important mechanism of endothelial repair [9]. These EPCs may play an important role in endothelial maintenance and vascular healing in health and disease, and

\section{Ciomed Central}

(c) 2015 Hong et al. Open Access This article is distributed under the terms of the Creative Commons Attribution 4.0 International License (http://creativecommons.org/licenses/by/4.0/), which permits unrestricted use, distribution, and reproduction in any medium, provided you give appropriate credit to the original author(s) and the source, provide a link to the Creative Commons license, and indicate if changes were made. The Creative Commons Public Domain Dedication waiver (http://creativecommons.org/publicdomain/zero/1.0/) applies to the data made available in this article, unless otherwise stated. 
are emerging as important biomarkers of prognosis in atherosclerosis $[10,11]$. Previous studies have employed two main methods to study EPCs in humans: 1) flow cytometric quantification of circulating CD34+ haematopoietic progenitors, usually co-expressing additional surface markers including CD133 and/or vascular endothelial growth factor receptor 2 (VEGFR2) [12]; and 2) quantification of circulating myeloid-derived EPC colony forming units (EPC-CFU) in angiogenic medium [12]. Little is known, however, about the impact of SV on these repair processes, despite concerns that vascular dysfunction is an important late sequelae of vasculitis in children [13, 14] and adults [15].

We have previously postulated that there is an unfavourable balance between endothelial injury and repair in children with SV [16], and that aging and dyslipidaemia also influence this balance [17]. We previously demonstrated evidence of excessive endothelial injury in children with SV: elevated numbers of circulating endothelial cells (CECs) [16], and increased circulating endothelial microparticles (EMPs) [16, 18]. It is possible that children mount an attempted adaptive response to this excessive endothelial injury, since we also observed increased circulating CD34 + CD133 + VEGFR2 + EPCs using flow cytometric analysis of peripheral blood monocytes in children with active vasculitis [16]. The functional relevance of this possible adaptive haematopoietic EPC response in paediatric SV has not yet been established, however. In the light of our previous findings, we hypothesised that the significant inflammatory milieu associated with SV would adversely affect EPC function, resulting in defective colony formation, adhesion and ability to integrate into vascular networks. The aims of the current study, therefore, were to: 1) investigate the relationship between disease activity and EPC function in children with SV; and 2) to study the potential influence of systemic inflammation on EPC function by investigating the effects of hyperthermia and TNF- $\alpha$ on EPC function in vitro.

\section{Methods}

\section{Patients and controls}

We performed a cross-sectional study of unselected children with SV with different levels of disease activity attending a single center (Great Ormond Street Hospital NHS Foundation Trust, London) between October 2008 and December 2014. Parental consent was obtained for all children involved in the study, which was approved by the Institutional Ethics Committee (see acknowledgements for details). Inclusion criteria for children with SV were as follows: age $<18$ years, a diagnosis of SV confirmed by histopathologic and/or arteriographic assessment, and secondary causes of vasculitis excluded (infection, other connective tissue disease, or malignancy). Control samples were obtained from healthy sex- and age-similar children; adult healthy controls were members of staff within our laboratory (median age 33 years, range 22-35 years; one female). All participating subjects provided written, fullyinformed consent.

Vasculitis subtype was classified using the EULAR/ PRINTO/PReS classification criteria for paediatric vasculitides [19] for: polyarteritis nodosa (PAN), granulomatosis with polyangiitis (GPA, formerly Wegener's granulomatosis), and Takayasu arteritis (TA). Kawasaki disease (KD) was defined as patients fulfilling at least five of six of the American Heart Association criteria for KD [20]. Microscopic polyangiitis (MPA) was defined according to the Chapel Hill definitions [21]. Patients with Behçet's disease (BD) fulfilled the International Study Group for Behçet's Disease criteria [22]. Disease activity was assessed using the Paediatric Vasculitis Activity Score (PVAS) [16, 19, 23, 24] which is shown in detail in Additional file 1 (Paediatric Vasculitis Activity Score) and Additional file 2 (glossary and scoring for PVAS). Active vasculitis was defined as a score greater than zero for PVAS items attributable to vasculitis that newly appeared or worsened during the preceding four weeks, and for which other causes such as infection were excluded [16, 24]. Patients in remission had a PVAS of 0/63. Routine laboratory markers [erythrocyte sedimentation rate (ESR) normal range $0-10 \mathrm{~mm} / \mathrm{h}$, and C-reactive protein (CRP) normal range $<20 \mathrm{mg} / \mathrm{L}$ ] levels provided adjunctive information regarding systemic inflammation related to systemic vasculitis activity.

\section{Immunomagnetic bead extraction of circulating endothelial cells from peripheral blood}

CECs were extracted from whole blood using CD146coated immunomagnetic beads using an international consensus protocol $[25,26]$. CECs extracted in this way were counted using a Nageotte chamber on a fluorescence microscope and were defined as Ulex europaeus lectin (Sigma-Aldrich, Doset, UK) bright cells that were $>10 \mu \mathrm{m}$ in size, with five or more magnetic beads attached.

\section{Functional assay of endothelial progenitor cells Endothelial progenitor cell colony-forming units}

EPC-CFUs were cultured with slight modification from methods previously described $[9,27]$. Briefly, peripheral blood mononuclear cells (PBMC) were isolated by density centrifugation (Lymphoprep TM, Axis Shield, Dundee, UK). After purification with three washing steps, $2 \times 10^{6}$ PBMCs were plated on fibronectin-coated 24well plates. Cells were cultured and maintained in endothelial growth media (EGM-2) culture medium supplemented with growth factors according to the manufacturer's recommendations (PromoCell, Heidelberg, Germany), plus $20 \%$ foetal calf serum (FCS) and $40 \mathrm{ng} / \mathrm{ml}$ of vascular endothelial growth factor (VEGF). After four days of culture, non-adherent cells were removed by washing with phosphate buffered saline (PBS). In some 
experiments TNF- $\alpha(10-50 \mathrm{ng} / \mathrm{ml})$ was added to the media. Culture medium was changed to maintain the cells in culture until day 7. The numbers of myeloid-EPC colony forming units (EPC-CFU), characterized by a cluster of cells surrounded by elongated spindled-shaped cells, were counted manually in a minimum of two wells in 24well plates by two independent observers who were unaware of the clinical profiles of the patients from whom the cells were derived. Results were expressed as average number of EPC-CFUs per well. Fig. 1a shows a representative EPC-CFU on day 7 from EPCs isolated from a fiveyear-old healthy control child. In selected samples, uptake of Di-I-acetylated low-density lipoprotein (Di-IAcLDL, Invitrogen, Paisley, UK) was confirmed, in line with other studies of this nature [10, 27].

\section{Matrigel assays: EPC cluster formation and incorporation assays}

Matrigel assays were employed to examine the ability of EPC to incorporate into endothelial capillary networks (hereafter referred to as the EPC-incorporation assay) [28] and the ability of EPC to form clusters (clusters of more than ten cells), a measure of EPC sprout formation (hereafter referred to as the EPC-cluster formation assay) [29]. Human umbilical vein endothelial cells (HUVEC; PromoCell) were cultured in EGM-2 medium supplemented with $2 \%$ FCS, hydrocortisone, fibroblast growth factor (FGF-2), VEGF, $\mathrm{R}^{3}$-insulin-like growth factor-1, epidermal growth factor, heparin, ascorbic acid, gentamycin and amphotericin $\mathrm{B}$, as supplied by the manufacturer (PromoCell) at $37{ }^{\circ} \mathrm{C}$ in $5 \% \mathrm{CO}_{2}$ in a humidified incubator. HUVECs at $80 \%$ confluency (passages 2-4) were used for experiments. Growth factor reduced Matrigel Matrix (Becton Dickinson Labware, Oxford, UK) was thawed and placed in 96 -well plates at $37^{\circ} \mathrm{C}$ for $30 \mathrm{~min}$ to solidify. EPCs were labeled with $2 \mu \mathrm{g} / \mathrm{ml}$ of Di-I-LDL to distinguish them from HUVECs.

For the EPC-cluster formation assay, 10,000 EPCs were plated in Matrigel; for the EPC-incorporation assay, DiIlabeled EPCs (3,000/well) were co-plated with HUVEC $(10,000 /$ well $)$ on top of a solidified Matrigel layer and cultured at $37^{\circ} \mathrm{C}$ for $18-20 \mathrm{~h}$ with EGM-2 medium.

Incorporation of EPC into capillary networks of HUVEC on Matrigel or EPC cluster formation was then examined with fluorescence microscopy. Five independent fields were assessed for each well and the mean numbers of EPCs incorporated into the HUVEC capillary networks and EPC clusters/x 100 fields were determined.

\section{Effects of TNF- $a$ and hyperthermia on EPC adhesion and incorporation into HUVEC networks \\ EPC adhesion assay}

EPC adhesion to fibronectin and HUVECs was assessed. EPCs were labeled with Di-I-LDL and $1 \times 10^{5}$ cells were placed on fibronectin-coated 96-well plates or on a monolayer of HUVECs pretreated with TNF- $\alpha$ (50 $\mathrm{ng} / \mathrm{ml})$ for six $h$, and incubated for one $h$ at $37^{\circ} \mathrm{C}$. Non-attached cells were gently removed by washing with PBS, and adherent EPCs were fixed with $4 \%$ paraformaldehyde and counted in ten random fields.

\section{XXT assay of cell viability in response to hyperthermia}

Cell viability under different experimental conditions was determined by XTT (xylin tetrazolium) assay, which is
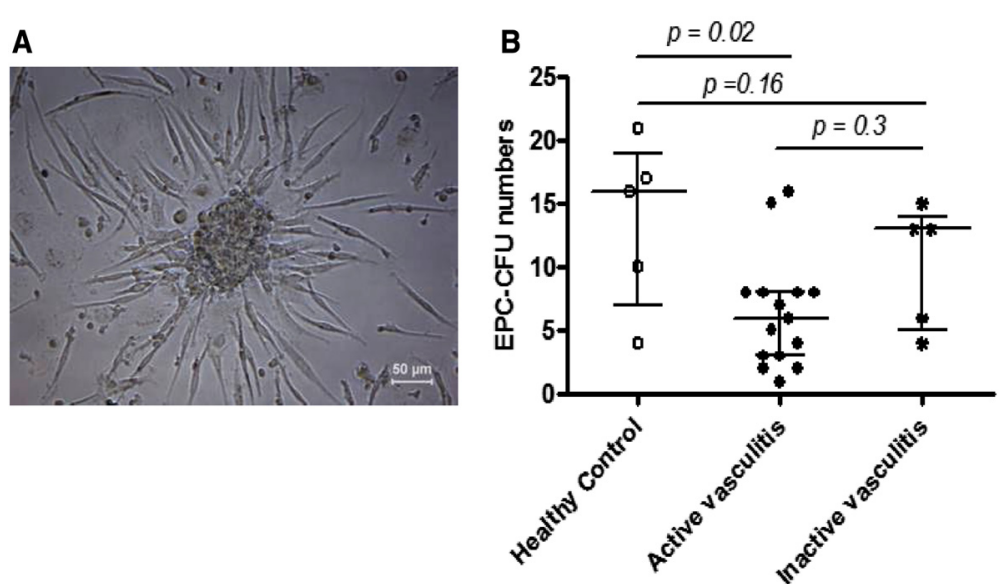

Fig. 1 Reduced endothelial progenitor cell-colony forming units (EPC-CFU) in children with active systematic vasculitis. a Representative image of EPC-colony forming unit (EPC-CFU from a healthy control child). $\mathbf{b}$ Comparison of EPC-CFU in children with active and inactive systematic vasculitis and child healthy controls. EPC-colony forming EPC-CFUs were reduced in 15 children with active disease compared to healthy control children but not in five children with inactive disease compared to healthy child controls $(p=0.3)$. The Kruskal-Wallis test was used to examine overall differences between the study groups followed by the Mann-Whitney $U$ test. $P$ values $<0.05$ were considered significant 
based on the ability of metabolically active cells to reduce the tetrazolium salt XTT to orange coloured compounds of formazan. EPC or HUVEC $\left(1 \times 10^{4}\right)$ were plated into 96-well plates in EGM-2. After $24 \mathrm{~h}$ at $37^{\circ} \mathrm{C}$, cells were incubated at $39^{\circ} \mathrm{C}$ for $2,4,18 \mathrm{~h}$, then replaced in a $37^{\circ} \mathrm{C}$ incubator for up to $18 \mathrm{~h}$ of total culture time. XTT was added to the culture medium and incubated at $37{ }^{\circ} \mathrm{C}$ for four $\mathrm{h}$. The formazan product was read at a wavelength of $545 \mathrm{~nm}$ with reference wavelength at $690 \mathrm{~nm}$.

\section{Statistical analysis}

All in vitro experiments were performed in triplicate unless otherwise stated, and values are presented as mean \pm standard error of the mean unless otherwise specified. Statistical differences for in vitro experiments between groups were determined by two-way analysis of variance (ANOVA), followed by unpaired two-tailed $T$-test. Patient demographics are summarized as median and range. The Kruskal-Wallis test was used to examine overall differences between the study groups followed by the Mann-Whitney $U$ test. P-values of less than 0.05 were regarded as significant. All analysis was performed using SPSS version 22.

\section{Results}

\section{Patients and controls}

We studied 20 unselected consecutive patients with a diagnosis of SV; the median age at time of study was 12.0 (range 9.0-16.5) years; six patients were male. There were five paediatric healthy controls (two male, three female) of median age four years (range, 3.6-10 years). Fifteen children had active SV $(\mathrm{n}=8$ PAN; $\mathrm{n}=4$ GPA; $\mathrm{n}=1$ EGPA; $\mathrm{n}=1$ $\mathrm{KD} ; \mathrm{n}=1$ unclassified but biopsy proven $\mathrm{SV}$ ), with median PVAS of 4/63 (range 4-26/63); five children had inactive SV ( $\mathrm{n}=4$ with GPA; and $\mathrm{n}=1$ Behçet's disease) with a PVAS of $0 / 63$ in all. The clinical features of the vasculitis patients are summarized in Table 1 . Median follow up for those with active disease was nine months (6-36 months); median follow up for those with inactive disease was 12 months (6-24 months).

Patients with clinically active vasculitis had evidence of endothelial injury, with an increased median CEC count of $88(8-420)$ cells $/ \mathrm{ml}$, and systemic inflammation as indicated by a median ESR of $73(11-137) \mathrm{mm} / \mathrm{h}$ and a CRP of 18.5 (5-270) mg/L; for children with inactive disease median CEC count was 16 (0-40) cells/ml, median ESR was $3(3-37) \mathrm{mm} / \mathrm{h}$, and median CRP was 5 (5-16) $\mathrm{mg} / \mathrm{L}$. For healthy controls there was a median CEC count of 24 $(0-80)$ cells/ml; these healthy paediatric controls did not have CRP or ESR performed.
Table 1 Patient characteristics, baseline laboratory parameters, circulating endothelial cell counts and treatment in 20 children with systemic vasculitis

\begin{tabular}{|c|c|c|}
\hline Demographic data & Active PSV $(n=15)$ & Inactive PSV $(n=5)$ \\
\hline Median age, years (range) & $12(7-16.5)$ & $12(9-11.6)$ \\
\hline Sex M/F & $5 \mathrm{M}: 10 \mathrm{~F}$ & $1 \mathrm{M}: 4 \mathrm{~F}$ \\
\hline Classification & $\begin{array}{l}\mathrm{n}=8 \text { PAN; } \mathrm{n}=4 \mathrm{GPA} \\
\mathrm{n}=1 \mathrm{EGPA} ; \mathrm{n}=1 \mathrm{KD} ; \\
\mathrm{n}=1 \text { unclassified SV }\end{array}$ & $\begin{array}{l}\mathrm{n}=4 \mathrm{GPA} ; \mathrm{n}=1 \\
\text { Behçet's disease }\end{array}$ \\
\hline $\mathrm{ESR}, \mathrm{mm} / \mathrm{h}$ (median, range) & $73(11-137)$ & $3(3-37)$ \\
\hline CRP, mg/L (median, range) & $18.5(5-270)$ & $5(5-16)$ \\
\hline $\begin{array}{l}\text { CEC count, cells/ml } \\
\text { (median, range) }\end{array}$ & $88(8-420)$ & $16(0-40)$ \\
\hline \multicolumn{3}{|l|}{ Treatment (n) } \\
\hline Cyclophosphamide & 5 & 2 \\
\hline Corticosteroids & 11 & 3 \\
\hline MMF & 1 & 2 \\
\hline Azathioprine & 0 & 1 \\
\hline Colchicine & 0 & 1 \\
\hline Rituximab & 1 & 0 \\
\hline
\end{tabular}

Classification of the vasculitic syndromes was based on the recent EULAR/ PRINTO/PRES classification criteria for pediatric vasculitis [19]. KD was identified based on five of six of the American Heart Criteria. Immunomagnetic bead extraction was used for enumeration of circulating endothelial cells (CEC). Treatments summarised were received at any point of the patients' disease course. PAN polyarteritis nodosa, KD Kawasaki disease, GPA granulomatosis with polyangiitis, EGPA eosinophilic granulomatosis with polyangiitis, ESR erythrocyte sedimentation rate, CRP C-reactive protein, MMF mycophenolate mofetil

\section{EPCs from children with active vasculitis have decreased} colony-forming capacity

EPC-CFUs were reduced in 15 children with active vasculitis (median 6/well; range 1-16/well) compared to healthy control children (median 16/well; range 4-21/ well), $\mathrm{p}=0.02$ and also (non-significantly) lower than children with inactive vasculitis (median 13/well; range 4-15/well), $p=0.16$ (Fig. 1b). There was no significant difference in EPC-CFU among the five children with inactive vasculitis compared to healthy child controls $(\mathrm{p}=0.3$; Fig. 1b).

\section{EPCs from children with active vasculitis demonstrate decreased cluster formation on Matrigel}

EPCs cultured for seven days were plated on Matrigelcoated wells to assess EPC cluster formation (clusters of EPCs containing more than ten cells), an inherent angiogenic functional property of EPCs and a prelude to vascular sprouting (Fig. 2a, and insert). EPC cluster formation was significantly lower in 15 children with active vasculitis (median $738 / \mathrm{mm}^{2}$; range $0-2,813$ ) compared to five healthy control children (median 2,386 $/ \mathrm{mm}^{2}$; range $1,522-2,652) ; \mathrm{p}=0.01$ and also lower (non-significantly) 

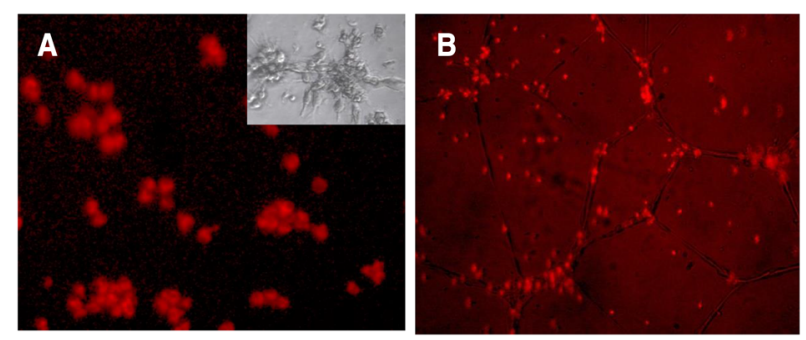

D

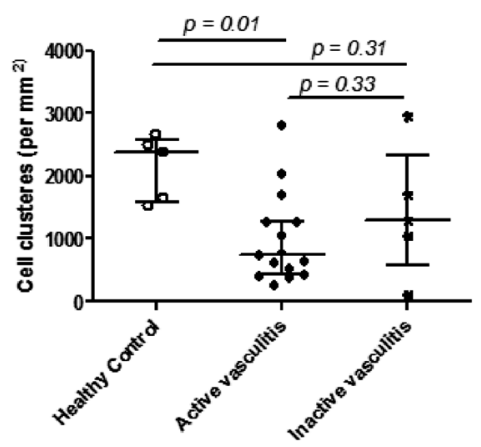

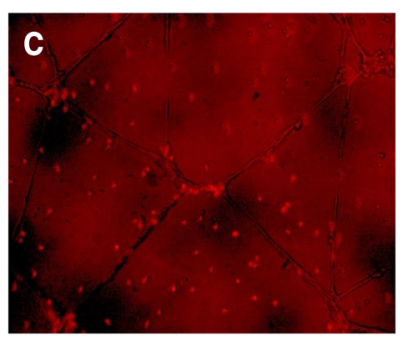

E

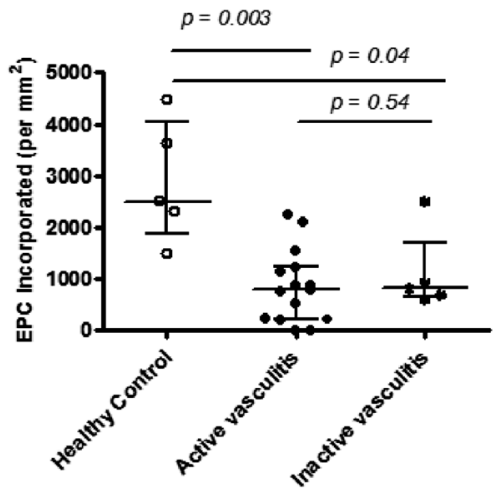

Fig. 2 Reduced incorporation of endothelial progenitor cells (EPCs) into endothelial capillary network and cluster formation on Matrigel in children with systemic vasculitis. a Representative image of EPC cluster formation on Matrigel. The inset shows an example of a sprouting EPC. $\mathbf{b}$ and $\mathbf{c}$ Representative images of the incorporation of EPCs from a healthy child (b), and a child with active granulomatosis with polyangiitis (c) into an endothelial capillary network on Matrigel. $\mathbf{d}$ Comparison of the number of EPC clusters with active and inactive systemic vasculitis and child healthy controls. The number of EPC clusters was reduced for 15 children with active disease compared with healthy control children ( $p=0.01)$; cells clusters in the inactive vasculitis group did not differ significantly from healthy controls. e EPC incorporation into HUVEC capillary networks on Matrigel in children with active and inactive systematic vasculitis and child healthy controls. Compared to five healthy control children, the number of EPC incorporated into HUVEC vascular networks on Matrigel was decreased for 15 children with active vasculitis $(p=0.003)$ and five children with inactive vasculitis $(p=0.04)$. The Kruskal-Wallis test was used to examine overall differences between the study groups followed by the Mann-Whitney $U$ test. $P$ values $<0.05$ were considered significant. HUVEC human umbilical vein endothelial cell

than children with inactive vasculitis (median $1,295 / \mathrm{mm}^{2}$; range 100-2,955; $\mathrm{p}=0.31$; Fig. $2 \mathrm{~b}$ ). There was no significant difference in EPC cluster formation between children with inactive vasculitis and healthy controls $(\mathrm{p}=0.33)$.

\section{EPCs from children with active vasculitis demonstrate} decreased incorporation into HUVEC networks

We next performed a Matrigel assay to investigate the ability of EPCs to incorporate into HUVEC vascular networks. Co-culture of EPCs (from systemic vasculitis patients or healthy controls) and HUVECs on Matrigel led to the formation of vascular tubule networks (Fig. 2c and $\mathrm{d}$ ). However, as summarised in Fig. 2e, the number of EPC incorporated into HUVEC vascular networks on Matrigel was decreased for 15 children with active vasculitis (median $795 / \mathrm{mm}^{2}$; range $0-2,235 / \mathrm{mm}^{2} ; \mathrm{p}=0.003$ ) and five children with inactive vasculitis (median $814 / \mathrm{mm}^{2}$; 596 $\left.2,500 / \mathrm{mm}^{2} ; \mathrm{p}=0.04\right)$, compared to five healthy control children (median 2,500/ $\mathrm{mm}^{2}$; range $1,478-4,478 / \mathrm{mm}^{2}$ ).
TNF-a reduces EPC incorporation into HUVEC networks

We next assessed the effect of TNF- $\alpha$ on the function of EPCs, since this inflammatory cytokine has been implicated in the pathogenesis of many forms of SV in children and adults [30, 31]. EPC were pre-treated with $10 \mathrm{ng} / \mathrm{ml}$ TNF- $\alpha$ for three days of EPC culture, then EPC were collected and the Matrigel assay was performed. The numbers of EPC incorporated into HUVEC vascular networks, and EPC clusters on Matrigel were significantly reduced after pre-treatment with TNF- $\alpha(\mathrm{p}=0.02$ and $\mathrm{p}=0.008$, respectively, Fig. $3 \mathrm{a}$ and b). In contrast, TNF- $\alpha$ (10-100 ng/ml) increased tube formation of HUVECs, similar to the effect of VEGF, an effect that was blocked by $10 \mu \mathrm{g} / \mathrm{ml}$ infliximab (a chimeric monoclonal antibody against TNF- $\alpha$; data not shown).

\section{TNF-a reduces EPC adhesion by decreasing CD18/CD11b expression}

We then examined whether the inhibitory effect of TNF- $\alpha$ on EPC vasculogenesis was due to alteration of the adhesiveness of cultured human EPCs to the activated endothelial cells and/or the extracellular matrix. EPCs were again pre-treated with $10 \mathrm{ng} / \mathrm{ml}$ TNF- $\alpha$ for three days, detached 


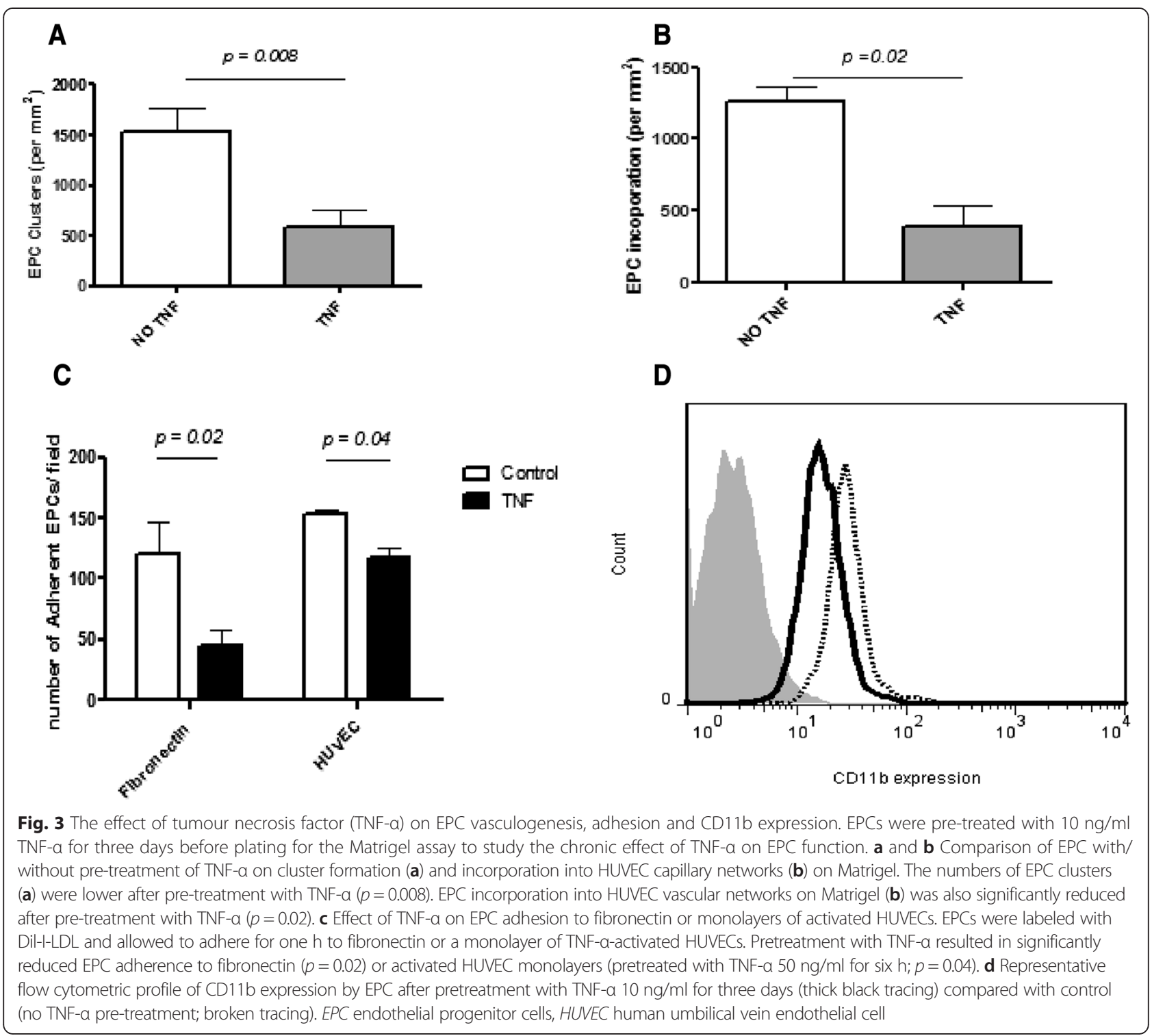

with $0.25 \%$ trypsin, and then re-plated onto fibronectincoated dishes or HUVEC monolayers. EPCs pre-treated with TNF- $\alpha$ exhibited a significant decrease in the number of adhesive cells at 60 min compared with control (Fig. 3c): adhesion to fibronectin at baseline $120 \pm 50$ versus $44.7 \pm$ 17.9 post exposure to TNF- $\alpha ; \mathrm{p}=0.02$ and adhesion to activated HUVEC monolayers at baseline $152.7 \pm 10.5$, versus $118.7 \pm 17.4$ after TNF- $\alpha, \mathrm{p}=0.04$.

Since EPCs are known to migrate to, and accumulate at, the site of tissue injury where they express complementary sets of surface receptors (CD11b/CD18, CD54) that could influence adhesion at these sites [32], using flow cytometry we next investigated whether TNF- $\alpha$ would alter the expression of these surface receptors on EPC. Pre-treatment with TNF- $\alpha$ down regulated the expression of CD11b (Fig. 3d), but increased that of CD54, and had no effect on CD146 or CD34 (data not shown).
Prolonged hyperthermia impairs HUVEC angiogenesis and reduces EPC cluster formation

Sustained/prolonged pyrexia is an important clinical feature of virtually all chronic inflammatory diseases, including SV. We therefore investigated the influence of hyperthermia on HUVEC vascular network formation and EPC cluster formation. HUVECs were initially incubated in Matrigel for $60 \mathrm{~min}$ at $37^{\circ} \mathrm{C}$ to allow their adhesion, followed by exposure to hyperthermia $\left(39^{\circ} \mathrm{C}\right)$ for $2-18 \mathrm{~h}$. As shown in Fig. 4a, prolonged exposure to hyperthermia resulted in a significant decrease in HUVEC tube formation at 4 and $18 \mathrm{~h}$. DiI-labeled EPCs plated on Matrigel at $39{ }^{\circ} \mathrm{C}$ for $2-18 \mathrm{~h}$ demonstrated decreased cluster formation by $4 \mathrm{~h}$ (Fig. $4 \mathrm{~b}$ ). To investigate whether these effects were the result of hyperthermia-induced cytotoxicity, we evaluated HUVEC and EPC viability after exposure to hyperthermia using a colorimetric assay; EPC or HUVECs 


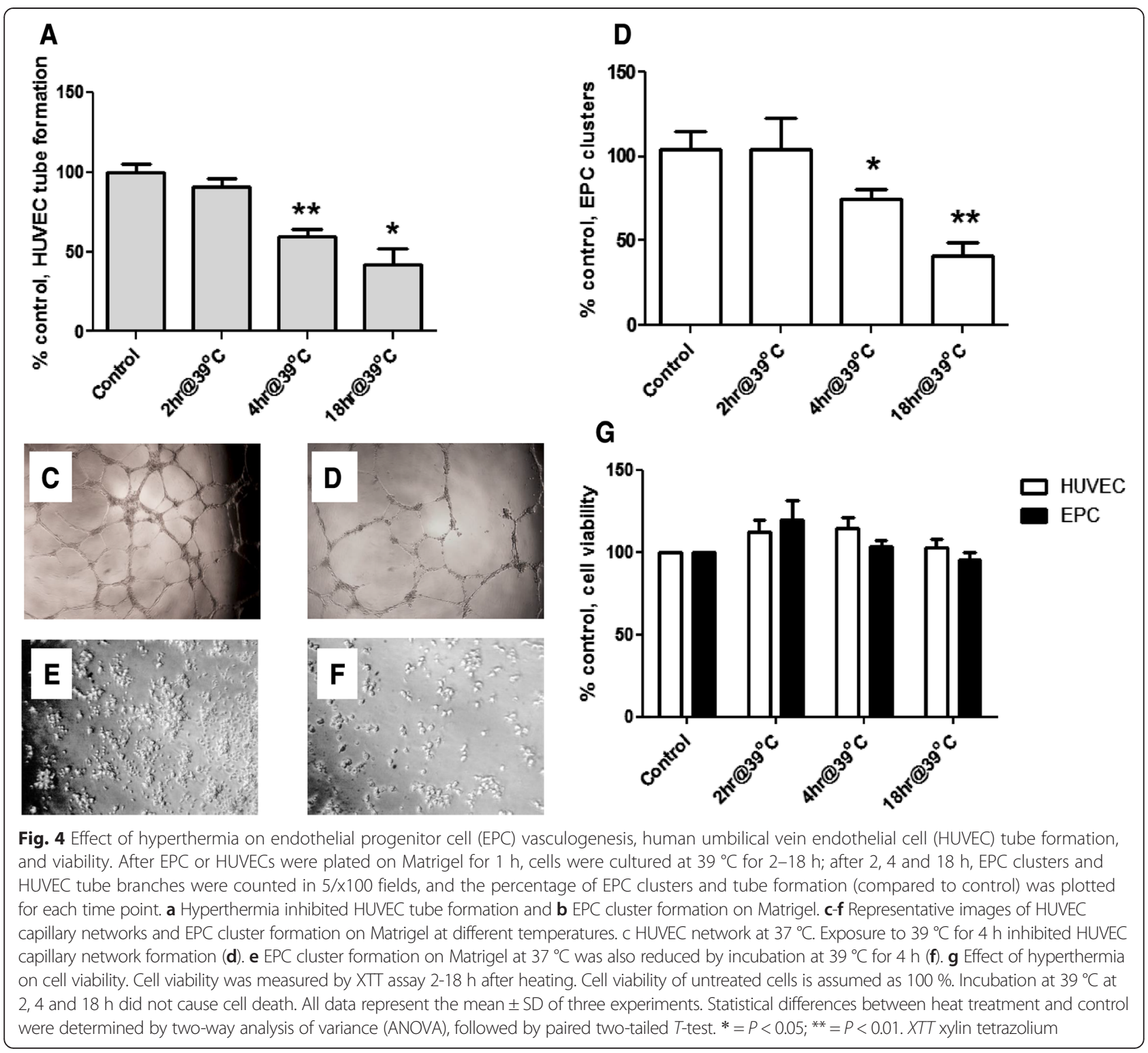

incubated under heat at different time points did not exhibit signs of increased cell death (Fig. 4c).

\section{Discussion}

In this study we demonstrated impaired endothelial repair capacity of EPC in children with SV. Using in vitro assays recapitulating in vivo morphogenesis events we have shown that EPC adherence, colony formation, and integration into endothelial networks were significantly impaired in children with active SV compared to patients with inactive vasculitis and healthy child controls. Our findings could suggest an impairment of endothelial repair capacity. As in adults with SV and other vascular disorders, it would be important to understand if this impaired endothelial repair response could contribute to cardiovascular sequelae.
Despite the lack of a consensus definition for an EPC [33], alterations in EPC biology have been linked to several human illnesses associated with cardiovascular morbidity and risk [34, 35]. Very little is currently known about EPC biology in patients with SV, although studies suggest that chronic inflammatory autoimmune diseases including rheumatoid or psoriatic arthritis [36], systemic lupus erythematosus [6,37], and systemic sclerosis [38] (amongst others) are associated with impairment in EPC function that could contribute to the excessive cardiovascular morbidity associated with these diseases. In SV, non-specific effects of chronic inflammation including pro-inflammatory cytokine milieu [39] and sustained pyrexia [40] could influence EPC biology in an adverse way, particularly when associated with other factors associated with the burden of these diseases such as uraemia 
[41], hypertension [42], dyslipidaemia [43], and impaired glucose tolerance [44]. Since a hallmark of SV is inflammation targeting endothelial cells, irrespective of the cause, impairment of EPCs may be of particular importance clinically since this would contribute further to an unfavourable balance between endothelial injury and repair.

Studies of EPCs in adults with SV relate mainly to antineutrophil cytoplasmic autoantibody (ANCA) associated vasculitis (AAV), and so far have provided apparently conflicting results, probably the result of patient and methodological heterogeneity and/or differences in treatment. Holmen et al. demonstrated that the numbers of EPCCFU were significantly decreased during active GPA as compared with remission, and suggested that impairment of EPC function was mediated in part by what they referred to as inflammatory circulating endothelial cells [45]. In contrast, De Groot et al. demonstrated no significant difference in circulating CD34+ haematopoietic stem cells and EPC-CFU numbers in patients with active AAV compared with healthy control levels [46]. Both these EPC parameters, however, increased after the institution of immunosuppressive therapy and disease remission in GPA patients. Závada et al. confirmed the observation of Holmen et al. of low EPC-CFU in adults with AAV, particularly in uraemic patients; but in contrast to the study of de Groot et al. found that neither institution of treatment nor entering remission increased the number of EPC-CFU [47]. In a separate study the same group went on to demonstrate that patients with AAV who had low EPC-CFU at first presentation had significantly higher rates of early disease relapse, for the first time suggesting that EPC levels might be important prognostically in AAV [48].

Only two studies have examined changes in EPCs in children with vasculitis $[16,49]$. In contrast to adults with AAV, we have previously shown that children with active SV respond to endothelial injury by release of CD34 + CD133 + KDR + EPCs into the circulation, possibly as an adaptive response to endothelial injury caused by vasculitis [16]. This observation was consistent with the findings of Nakatani et al. who observed a rise in circulating CD34 + CD133+ EPCs in the sub-acute phase of KD complicated by coronary artery lesions [49]. The findings of our current study, however, emphasise that CD34+ positive haematopoietic EPCs represent a different cell population from the monocytic EPCs that undoubtedly represent the cells that form the colonies and Matrigel clusters from PBMCs as defined in our present study, and many other studies [33]. The present findings, taken together with our previous studies $[16,18]$ suggest that in children with active vasculitis there is an unfavourable balance between endothelial injury and repair since there is increased endothelial injury reflected by an increase in CECs and EMPs and an additional disturbance in cells efficient for repair.
Our data suggest that chronic inflammation per se could account for impaired monocytic EPC function since we established that both TNF- $\alpha$ and hyperthermia impaired EPC function, in agreement with previous studies demonstrating an adverse effect of TNF- $\alpha$ on EPC function in adults with RA [50]. Indeed, there is also a considerable amount of indirect evidence supporting a role of TNF- $\alpha$ in the pathogenesis of systematic vasculitis [51-53]. As well as confirming this adverse effect of TNF- $\alpha$ on EPCs, for the first time we also demonstrated that TNF- $\alpha$ downregulated the expression of CD11b on EPC, providing a mechanism for reduced adhesion of EPC into vascular networks. This observation would not preclude alternative mechanisms, such as accelerated EPC senescence, that could also contribute to this EPC dysfunction [54-57].

Our findings have several implications. We now have the unique ability to explore the endothelium noninvasively, defining an imbalance between endothelial damage and repair capacity for children with SV. This multi-marker approach combining CEC, EMP and EPC measurement provides novel insights into endothelial dysfunction and moving forward could allow us to explore the prognostic relevance of this approach in individual patients studied longitudinally in multicentre collaborative studies. Future therapeutic strategies aiming to improve endothelial function, employing for instance statins, ACE inhibitors or PPAR-gamma agonists (amongst other potentially important drugs), could target the selective reduction of endothelial injury and/or the promotion of regenerative mechanisms, but ideally would address both sides of the injury/repair equation. At the individual level, such personalised therapeutic options could help reduce late cardiovascular morbidity associated with childhood vasculitis [13]. In that context it would be of considerable interest to prospectively examine the influence of altered endothelial repair responses in children with SV on late structural arterial injury [13], an ongoing concern for survivors of other childhood vasculitides such as KD [58].

Our study has limitations. Systemic vasculitis is rare in children and consequently the study population was relatively small and heterogeneous; that said, we did not observe any obvious difference in EPC function between different forms of vasculitis in this study, and have previously demonstrated that downstream endothelial injury processes are similar across different forms of paediatric vasculitides $[16,18,25,59]$. Additionally, the longitudinal effect of treatment on EPC responses was not examined in individual patients, but clearly it would be advantageous to do so in the future. Other limitations relate to the poor standardization of assays for EPCs, an inherent problem for all studies of this nature. Methodological issues and confusion created by the various definitions currently in use remain a major cause of apparent conflicting results regarding changes in EPC biology in human diseases. 
Standardisation of the methodology used to quantitate EPCs including an exact and consensus definition for EPCs is urgently needed to facilitate future studies [50].

\section{Conclusions}

In summary, two key findings from our study and previous work in this area are: 1) circulating EPCs are increased in response to active vasculitis in the young, a finding that contrasts with adults with SV; and 2) EPC function (ex vivo) is impaired. Whilst the clinical relevance of this observation remains undetermined, our findings could indicate an impaired endothelial repair capacity that, in the presence of ongoing endothelial injury, may further contribute to endothelial dysfunction. Future studies are now required to address the clinical implications of these observations in terms of late cardiovascular morbidity and the influence of treatment on EPC biology in children with systemic vasculitis.

\section{Additional files}

Additional file 1: Paediatric Vasculitis Activity Score. (PDF $51 \mathrm{~kb}$ )

Additional file 2: Glossary and scoring for PVAS. (PDF $61 \mathrm{~kb}$ )

\section{Abbreviations}

EPC: Endothelial progenitor cells; EPC-CFU: EPC colony forming unit; HUVEC: Human umbilical vein endothelial cell; SV: Systemic vasculitis.

\section{Competing interests}

The authors declare that they have no competing interests.

\begin{abstract}
Authors' contributions
$\mathrm{YH}$ designed the experiments, conducted all experiments, the analysis and interpretation of data, drafted, and edited the manuscript. DE acquired data and provided the clinical information, drafted and revised the manuscript. PB participated in conceiving the study, study design, coordination, interpretation of data, drafted the manuscript, and revised it critically for important intellectual content. NK contributed to the study design, interpretation of data, drafted, and revised the manuscript. All authors read and approved the final manuscript.
\end{abstract}

\section{Acknowledgements}

This study was supported in part by research funding from Arthritis Research UK to Y.H and an ARUK grant to D.E (grant 20164). All clinical material used in this study was collected in Great Ormond Street Hospital NHS Foundation Trust, London. Ethical approval was obtained from Institute of Child Health/Great Ormond Street Hospital Research Ethics Committee "Endothelial progenitor cells of vasculitis of the young". (project ethics number 04/Q0508/117).

Received: 19 March 2015 Accepted: 30 September 2015 Published online: 16 October 2015

\section{References}

1. Dillon MJ, Eleftheriou D, Brogan PA. Medium-size-vessel vasculitis. Pediatr Nephrol. 2010;25:1641-52.

2. Brogan PA. What's new in the aetiopathogenesis of vasculitis? Pediatr Nephrol. 2007;22:1083-94.

3. Savage CO. Vascular biology and vasculitis. APMIS Suppl. 2009;127:37-40

4. Tomasson G, Monach PA, Merkel PA. Thromboembolic disease in vasculitis. Curr Opin Rheumatol. 2009;21:41-6.

5. Choi JH, Kim KL, Huh W, Kim B, Byun J, Suh W, et al. Decreased number and impaired angiogenic function of endothelial progenitor cells in patients with chronic renal failure. Arterioscler Thromb Vasc Biol. 2004;24:1246-52.
6. Mohan S, Barsalou J, Bradley TJ, Slorach C, Reynolds JA, Hasni S, et al. Endothelial progenitor cell phenotype and function are impaired in childhood onset systemic lupus erythematosus. Arthritis Rheumatol. 2015;67:2257-62.

7. Sabatier F, Camoin-Jau L, Anfosso F, Sampol J, Dignat-George F. Circulating endothelial cells, microparticles and progenitors: key players towards the definition of vascular competence. J Cell Mol Med. 2009;13:454-71.

8. Dimmeler S, Zeiher AM. Vascular repair by circulating endothelial progenitor cells: the missing link in atherosclerosis? J Mol Med (Berl). 2004;82:671-7.

9. Asahara T, Murohara T, Sullivan A, Silver M, van der Zee R, Li T, et al. Isolation of putative progenitor endothelial cells for angiogenesis. Science. 1997;275:964-7.

10. Hill JM, Zalos G, Halcox JP, Schenke WH, Waclawiw MA, Quyyumi AA, et al. Circulating endothelial progenitor cells, vascular function, and cardiovascular risk. N Engl J Med. 2003;348:593-600.

11. Werner N, Kosiol S, Schiegl T, Ahlers P, Walenta K, Link A, et al. Circulating endothelial progenitor cells and cardiovascular outcomes. N Engl J Med. 2005;353:999-1007.

12. Hirschi KK, Ingram DA, Yoder MC. Assessing identity, phenotype, and fate of endothelial progenitor cells. Arterioscler Thromb Vasc Biol. 2008;28:1584-95.

13. Cheung YF, Brogan PA, Pilla CB, Dillon MJ, Redington AN. Arterial distensibility in children and teenagers: normal evolution and the effect of childhood vasculitis. Arch Dis Child. 2002;87:348-51.

14. Burns JC. Kawasaki disease. Oxford textbook of vasculitis. 2014;373-98.

15. Mukhtyar C, Brogan P, Luqmani R. Cardiovascular involvement in primary systemic vasculitis. Best Pract Res Clin Rheumatol. 2009;23:419-28.

16. Clarke LA, Hong Y, Eleftheriou D, Shah V, Arrigoni F, Klein NJ, et al. Endothelial injury and repair in systemic vasculitis of the young. Arthritis Rheum. 2010;62:1770-80

17. Fabbri-Arrigoni Fl, Clarke L, Wang G, Charakida M, Ellins E, Halliday N, et al. Levels of circulating endothelial cells and colony-forming units are influenced by age and dyslipidemia. Pediatr Res. 2012;72:299-304.

18. Brogan PA, Shah V, Brachet C, Harnden A, Mant D, Klein N, et al. Endothelial and platelet microparticles in vasculitis of the young. Arthritis Rheum. 2004;50:927-36.

19. Ozen S, Pistorio A, lusan SM, Bakkaloglu A, Herlin T, Brik R, et al. EULAR/ PRINTO/PRES criteria for Henoch-Schonlein purpura, childhood polyarteritis nodosa, childhood Wegener granulomatosis and childhood Takayasu arteritis: Ankara 2008. Part II: final classification criteria. Ann Rheum Dis. 2010;69:798-806

20. Newburger JW, Takahashi M, Gerber MA, Gewitz MH, Tani LY, Burns JC, et al. Diagnosis, treatment, and long-term management of Kawasaki disease: a statement for health professionals from the Committee on Rheumatic Fever, Endocarditis, and Kawasaki Disease, Council on Cardiovascular Disease in the Young, American Heart Association. Pediatrics. 2004;1 14:1708-33.

21. Jennette JC, Falk RJ, Andrassy K, Bacon PA, Churg J, Gross WL, et al. Nomenclature of systemic vasculitides. Proposal of an international consensus conference. Arthritis Rheum. 1994;37:187-92.

22. Criteria for diagnosis of Behcet's disease. International Study Group for Behcet's Disease. Lancet. 1990;335:1078-80.

23. Demirkaya E, Ozen S, Pistorio A, Galasso R, Ravelli A, Hasija R, et al. Performance of Birmingham Vasculitis Activity Score and disease extent index in childhood vasculitides. Clin Exp Rheumatol. 2012;30 Suppl 70:S162-8.

24. Luqmani RA, Bacon PA, Moots RJ, Janssen BA, Pall A, Emery P, et al. Birmingham Vasculitis Activity Score (BVAS) in systemic necrotizing vasculitis. QJM. 1994;87:671-8.

25. Clarke LA, Shah V, Arrigoni F, Eleftheriou D, Hong Y, Halcox J, et al. Quantitative detection of circulating endothelial cells in vasculitis: comparison of flow cytometry and immunomagnetic bead extraction. J Thromb Haemost. 2008;6:1025-32.

26. Woywodt A, Streiber F, de Groot K, Regelsberger H, Haller H, Haubitz M, Circulating endothelial cells as markers for ANCA-associated small-vessel vasculitis. Lancet. 2003;361:206-10.

27. Vasa M, Fichtlscherer S, Aicher A, Adler K, Urbich C, Martin H, et al. Number and migratory activity of circulating endothelial progenitor cells inversely correlate with risk factors for coronary artery disease. Circ Res. 2001;89:E1-7.

28. Tepper OM, Galiano RD, Capla JM, Kalka C, Gagne PJ, Jacobowitz GR, et al. Human endothelial progenitor cells from type II diabetics exhibit impaired proliferation, adhesion, and incorporation into vascular structures. Circulation. 2002;106:2781-6.

29. Moonen JR, de Leeuw K, van Seijen XJ, Kallenberg CG, van Luyn MJ, Bijl M, et al. Reduced number and impaired function of circulating progenitor cells in patients with systemic lupus erythematosus. Arthritis Res Ther. 2007;9:R84. 
30. Bartolucci P, Ramanoelina J, Cohen P, Mahr A, Godmer P, Le Hello C, et al. Efficacy of the anti-TNFa antibody infliximab against refractory systemic vasculitides: an open pilot study on 10 patients. Rheumatology. 2002;41:1126-32.

31. Eleftheriou D, Melo M, Marks SD, Tullus K, Sills J, Cleary G, et al. Biologic therapy in primary systemic vasculitis of the young. Rheumatology. 2009;48:978-86.

32. Henrich D, Zimmer S, Seebach C, Frank J, Barker J, Marzi I. Trauma-activated polymorphonucleated leukocytes damage endothelial progenitor cells: probable role of CD11b/CD18-CD54 interaction and release of reactive oxygen species. Shock. 2011;36:216-22.

33. Yoder MC. Human endothelial progenitor cells. Cold Spring Harb Perspect Med. 2012;2:a006692

34. Resch T, Pircher A, Kahler CM, Pratschke J, Hilbe W. Endothelial progenitor cells: current issues on characterization and challenging clinical applications. Stem Cell Rev. 2011;8:926-39.

35. Asahara $\mathrm{T}$, Kawamoto $\mathrm{A}$, Masuda $\mathrm{H}$. Concise review: circulating endothelial progenitor cells for vascular medicine. Stem Cells. 2011;29:1650-5.

36. Ablin JN, Goldstein Z, Aloush V, Matz H, Elkayam O, Caspi D, et al. Normal levels and function of endothelial progenitor cells in patients with psoriatic arthritis. Rheumatol Int. 2009;29:257-62.

37. Castejon R, Jimenez-Ortiz C, Valero-Gonzalez S, Rosado S, Mellor S, Yebra-Bango M. Decreased circulating endothelial progenitor cells as an early risk factor of subclinical atherosclerosis in systemic lupus erythematosus. Rheumatology. 2014;53:631-8.

38. Kuwana M, Okazaki Y. Brief report: impaired in vivo neovascularization capacity of endothelial progenitor cells in patients with systemic sclerosis. Arthritis Rheumatol. 2014;66:1300-5.

39. Harper L, Williams JM, Savage CO. The importance of resolution of inflammation in the pathogenesis of ANCA-associated vasculitis. Biochem Soc Trans. 2004:32:502-6.

40. Sachs D, Langevitz P, Morag B, Pras M. Polyarteritis nodosa and familial Mediterranean fever. Rheumatology. 1987;26:139-41.

41. de Groot K, Bahlmann FH, Sowa J, Koenig J, Menne J, Haller H, et al. Uremia causes endothelial progenitor cell deficiency. Kidney Int. 2004;66:641-6.

42. Riancho-Zarrabeitia L, Zurbano F, Gomez-Roman J, Martinez-Menaca A, Lopez M, Hernaíndez MA, et al. Isolated pulmonary vasculitis: case report and literature review. Semin Arthritis Rheum. 2014;44:1-4

43. Cohen Tervaert JW. Cardiovascular disease due to accelerated atherosclerosis in systemic vasculitides. Best Pract Res Clin Rheumatol. 2013;27:33-44.

44. Petermann Smits DR, Wilde $B$, Kianersi Adegani $M$, de Jongh $H$, van Paassen P, Cohen Tervaert JW. Metabolic syndrome in ANCA-associated vasculitis. Rheumatology. 2013;52:197-203.

45. Holmen C, Elsheikh E, Stenvinkel P, Qureshi AR, Pettersson E, Jalkanen S, et al. Circulating inflammatory endothelial cells contribute to endothelial progenitor cell dysfunction in patients with vasculitis and kidney involvement. J Am Soc Nephrol. 2005;16:3110-20.

46. de Groot K, Goldberg C, Bahlmann FH, Woywodt A, Haller H, Fliser D, et al. Vascular endothelial damage and repair in antineutrophil cytoplasmic antibody-associated vasculitis. Arthritis Rheum. 2007:56:3847-53.

47. Zavada J, Kideryova L, Pytlik R, Vankova Z, Tesar V. Circulating endothelial progenitor cells in patients with ANCA-associated vasculitis. Kidney Blood Press Res. 2008;31:247-54.

48. Zavada J, Kideryova L, Pytlik R, Hruskova Z, Tesar V. Reduced number of endothelial progenitor cells is predictive of early relapse in anti-neutrophil cytoplasmic antibody-associated vasculitis. Rheumatology (Oxford). 2009:48:1197-201.

49. Nakatani K, Takeshita S, Tsujimoto H, Kawamura Y, Tokutomi T, Sekine I. Circulating endothelial cells in Kawasaki disease. Clin Exp Immunol. 2003;131:536-40.

50. Ablin JN, Boguslavski V, Aloush V, Elkayam O, Paran D, Caspi D, et al. Effect of anti-TNFalpha treatment on circulating endothelial progenitor cells (EPCs) in rheumatoid arthritis. Life Sci. 2006:79:2364-9.

51. Sokumbi O, Wetter DA, Makol A, Warrington KJ. Vasculitis associated with tumor necrosis factor-a inhibitors. Mayo Clin Proc. 2012;87:739-45.

52. Hasegawa M, Nishii C, Ohashi A, Tomita M, Nakai S, Murakami K, et al. Expression of tumor necrosis factor receptors on granulocytes in patients with myeloperoxidase anti-neutrophil cytoplasmic autoantibody-associated vasculitis Expression of tumor necrosis factor receptors on granulocytes in patients with myeloperoxidase anti-neutrophil cytoplasmic autoantibody-associated vasculitis. Nephron Clin Pract. 2009:113:c222-33.
53. Jarrot PA, Kaplanski G. Anti-TNF-alpha therapy and systemic vasculitis. Mediat Inflamm. 2014:2014:493593.

54. Yuan Q, Hu CP, Gong ZC, Bai YP, Liu SY, Li YJ, et al. Accelerated onset of senescence of endothelial progenitor cells in patients with type 2 diabetes mellitus: role of dimethylarginine dimethylaminohydrolase 2 and asymmetric dimethylarginine. Biochem Biophys Res Commun. 2015;458:869-76.

55. Vassallo PF, Simoncini SP, Ligi I, Chateau AL, Bachelier R, Robert SP, et al. Accelerated senescence of cord blood endothelial progenitor cells in premature neonates is driven by SIRT1 decreased expression. Blood. 2014;123:2116-26.

56. Paschalaki KE, Starke RD, Hu Y, Mercado N, Margariti A, Gorgoulis VG, et al. Dysfunction of endothelial progenitor cells from smokers and chronic obstructive pulmonary disease patients due to increased DNA damage and senescence. Stem Cells. 2013;31:2813-26.

57. Minamino T, Komuro I. Vascular cell senescence contribution to atherosclerosis. Circ Res. 2007;100:15-26.

58. Shah V, Christov G, Mukasa T, Brogan KS, Wade A, Eleftherriou D, et al. Cardiovascular status after Kawasaki disease in the UK. Heart. 2015;101:1646-55.

59. Eleftheriou D, Hong Y, Klein NJ, Brogan PA. Thromboembolic disease in systemic vasculitis is associated with enhanced microparticle-mediated thrombin generation. J Thromb Haemost. 2011;9:1864-7.

\section{Submit your next manuscript to BioMed Central and take full advantage of:}

- Convenient online submission

- Thorough peer review

- No space constraints or color figure charges

- Immediate publication on acceptance

- Inclusion in PubMed, CAS, Scopus and Google Scholar

- Research which is freely available for redistribution 